\title{
Corticosterone at fledging depends on nestling condition, not on parental desertion
}

This article was published in the following Dove Press journal:

Open Access Animal Physiology

12 October 2010

Number of times this article has been viewed

\section{Petra Quillfeldt' \\ Maud Poisbleau ${ }^{1,2}$ \\ Ingrid Schwabl ${ }^{3}$ \\ Olivier Chastel ${ }^{4}$ \\ Juan F Masello'}

'Max-Planck-Institut für Ornithologie, Vogelwarte Radolfzell, Radolfzell, Germany; ${ }^{2}$ University of Antwerp, Campus Drie Eiken, Department Biology - Ethology, Antwerp (Wilrijk), Belgium; ${ }^{3}$ Max-Planck-Institut für Ornithologie, Eberhard-GwinnerStraße, Seewiesen, Germany; ${ }^{4}$ Centre d'Etudes Biologiques de Chizé, Centre National de la Recherche Scientifique, Deux-Sèvres, France

Correspondence: Petra Quillfeldt Max-Planck-Institut für Ornithologie, Vogelwarte Radolfzell, Schlossallee 2, 783 I5 Radolfzell, Germany Fax +49 7732 I50I39 Email petra.quillfeldt@gmx.de

\begin{abstract}
In some burrow-nesting birds, fledging is preceded by a strong rise in circulating corticosterone levels. Because the parents may desert nestlings in these species, this rise may be internally triggered or it may be a response to failing adult attention. We followed nestling thin-billed prions throughout the pre-fledging period in three seasons, 2005-2007. These seasons had contrasting oceanographic conditions, the sea surface temperature being warm in 2005 , intermediate in the fledging period in 2006, and cold in 2007. Accordingly, the food availability, reflected in chick peak masses and begging rates, was low throughout 2005, intermediate during 2006, and high throughout 2007. We observed that most caring parents attended thin-billed prion nestlings until they were fledgings in the seasons of food scarcity during 2005 and 2006. In contrast, chicks were left alone for a mean of 4 days before fledging in 2007 . The pre-fledging rise in corticosterone was lowest in the good year of 2007, even though most chicks were not attended during the pre-fledging period in that year. Our results thus indicate that CORT at fledging depends on nestling age and condition, not on parental desertion.
\end{abstract}

Keywords: Pachyptila belcheri, Southwest Atlantic, fledging, corticosterone, independence

\section{Introduction}

Glucocorticosteroids (GCs) of the hypothalamo-pituitary-adrenal axis play a role in association with both stressful events and daily life processes. ${ }^{1,2}$ In anticipation of energetically demanding phases, which often occur as part of the annual or daily routine, GCs change predictably. ${ }^{3}$ On the other hand, animals frequently experience less predictable events such as food shortages. In consequence, their organism also requires some changes in the relative investment in different fitness-related functions, such as body maintenance or reproduction. Corticosterone (CORT), which is the principal GC in bird, has been suggested as a potential mediator of such tradeoffs. It influences diverse body functions such as metabolism ${ }^{4}$ and immune responses. ${ }^{5}$ An increase in CORT was shown in responses to a wide range of stressors such as food shortage, ${ }^{6}$ contamination, ${ }^{7}$ and capture. ${ }^{8}$

A recent study explored the relative importance of unpredictable and predictable events in the regulation of CORT in a highly pelagic seabird, the thin-billed prion (Pachyptila belcheri). ${ }^{3}$ That study established that close to fledging, chicks rapidly increased basal CORT levels, and this increase was higher in unfed chicks than fed chicks. $^{3}$

Thin-billed prion parents raise only one chick per breeding attempt. Chicks are fed infrequently, often with intervals of several days. ${ }^{9-11}$ Adults carry out foraging trips of 1-8 days, ${ }^{11}$ resulting in intervals between feeds of $1-5$ days. The duration of the 
feeding trips depends on the prevailing ocean climate, with warm waters resulting in low food availability and, consequently, long foraging trips and low provisioning frequencies of thin-billed prions. ${ }^{12}$ The resulting differences in the amount of food delivered to the chick by a pair of adults are large, but most chicks will survive to fledging regardless. ${ }^{12}$ This situation presents a natural experiment, where chicks in different years reach the fledging age under strongly contrasting conditions. The study comparing recently fed versus unfed chicks ${ }^{3}$ suggested that the pre-fledging rise in CORT is influenced either by differences in nutrition, or that it may be a response to failing adult attention.

In the present study, we measured basal levels of plasma CORT in chicks of thin-billed prions during the preparation for fledging in three subsequent breeding seasons. The aim of the present study was to establish:

1. Whether the pre-fledging rise in CORT is influenced by differences in food availability, such as experienced during chronic food shortages; or

2. Whether the exaggerated rise observed in unfed chicks is a response to failing adult attention in the pre-fledging days.

\section{Materials and methods Study site and study species}

Fieldwork was carried out as part of ongoing studies of the breeding biology of thin-billed prions, between January and March of the years 2005-2007, at New Island Nature Reserve, Falkland Islands. ${ }^{13}$ Thin-billed prions are long-lived sub-Antarctic seabirds which lay a single-egg and show slow chick development. ${ }^{14}$ Thin-billed prions are burrow nesters, and we reached chicks and adults in their nest chambers via short access tunnels in the roof of each burrow, capped with removable stone lids. This system facilitated rapid access to chicks, reducing overall disturbance.

\section{Chick measurements}

Marked nests were monitored for eggs and hatching chicks. When eggs were found, the hatching date was estimated from the egg density, ${ }^{15}$ and the nest was not visited again until 3 days after the estimated hatching date. If chicks were present on our first visit, we determined the hatching dates of chicks (to the nearest day) by calibrating wing and tarsus length against wing growth in chicks of known age. Wing, tarsus, and tarsus lengths were measured every 3 days, using a stopped wing rule and callipers, respectively. Tail lengths were measured every 3 days from the time the feather starts protruding, using a feather rule.
Tarsus growth (from repeated measurements of 20-50 chicks over six seasons) ${ }^{16}$ was approximately linear until 30 days of age: tarsus $(\mathrm{mm})=15.468 \mathrm{~mm}+0.605 \mathrm{~mm} \times$ age (days); $\left(R^{2}=0.93\right.$, d.f. $\left.1468, F=19036, P<0.001\right)$. Wing growth until 30 days of age was best described by a quadratic regression: wing $(\mathrm{mm})=19.415 \mathrm{~mm}-0.569 \mathrm{~mm} \times$ age $($ days $)+0.110 \mathrm{~mm} \times(\text { age }(\text { days }))^{2} ;\left(R^{2}=0.94\right.$, d.f. 1498 , $F=10890, P<0.001)$. The median hatch dates and ranges in the three seasons were January 2, 2005 (December 26-January 12), January 2, 2006 (December 23-January 8) and 4 January 2007 (December 27-January 13). After hatch, chicks were brooded alternately by the parents for 3-8 days, before remaining in the nest on their own during the day. The parents return to feed their chicks at night, after feeding trips of $1-8$ days. ${ }^{11,16}$ Chicks were weighed daily to the nearest $1 \mathrm{~g}$ using a digital balance, during the duration of the field season. In 2005 and 2007, this included the entire chick-rearing period from hatching to fledging at the age of 49-56 days, while only chicks from ca. 20 days of age were measured in 2006 . Feeding rates (g/day) were estimated from the daily weights, by correcting the mass differences for metabolic mass loss, using published equations. ${ }^{15}$ We started with 149 chicks $(\mathrm{N}=57$ in 2005, 40 in 2006, and 52 in 2007), but sample sizes decrease for measurements of older chicks as some chicks moved from their nest chamber and were not reached in their burrows. As this was well before fledging, we do not think this behavior biased our results.

We calculated a body condition index for chicks aged at least 10 days, using the observed body mass (m), relative to a multiyear (2003-2006) mean mass for chicks of each age $\left(\mathrm{m}_{\text {mean }}\right)$, using the formula: $\mathrm{BC}$ index $=\mathrm{m} / \mathrm{m}_{\text {mean }} \times 100 .{ }^{17}$ $\mathrm{m}_{\text {mean }}$ was best described by the regression equation: $\mathrm{m}_{\text {mean }}$ $(\mathrm{g})=-0.0011 \mathrm{~g} \times \mathrm{age}^{3}+0.0056 \mathrm{~g} \times \mathrm{age}^{2}+5.075 \mathrm{~g} \times \mathrm{age}+$ $22.917 \mathrm{~g}$. In species with a pattern of peak mass and mass recession, like Procellariiformes and Psittaciformes, body condition indices relative to age are more adequate than mass controlled for measures of body size. In these chicks, growth of structural size and body mass does not occur in a parallel fashion (eg, approximate quadratic growth of mass, but logistic tarsus growth, with maximum tarsus often reached well before the end of the nestling stage).${ }^{18}$ Thus, mass versus structural size in chicks of these groups is not independent of chick age.

\section{Begging call recordings}

The vocal behavior of a subsample of nestlings aged 10-40 days $(\mathrm{N}=28$ in 2005, and 20 in both 2006 and 2007) was recorded overnight with a digital voice recorder placed 
outside the nest entrance, connected to an external microphone placed close to the nest chamber. Chicks start begging as soon as an adult arrived with food in the burrow. The recorders were switched on at 22:00 hours and recorded continuously for 8 hours. The recordings were transferred to a computer. Using the software CoolEdit 96 (Adobe, San Jose, CA), the duration of the begging sessions during first feeding events in a night was measured, and the total call number counted. Sometimes, several feedings take place during a night, but consistently with earlier studies, ${ }^{12,17}$ we analyzed only the first session per night. This way, the variation in begging behavior reflected the chick's need at the time of adult arrival. For each chick with a minimum of four recorded nights, we calculated the mean duration of the begging session and call number, which were used in the present analysis. ${ }^{19,20}$ The begging call recordings, chick weighing, and in some birds, radio-tracking ${ }^{11,16}$ were used to determine the presence of adults at nests in the pre-fledging period (ie, the days immediately preceding fledging). The number of nights from the last time an adult was registered to fledging of the chicks was recorded; for example, if a chick was attended in the night before fledging, the parameter "nights not attended" was set to 1 , but if chicks were not attended for one or several nights, accordingly higher. Results from radio-tracking confirmed presence/absence data obtained from chick weights.

\section{Blood sample collection and hormone analyses}

Blood samples $(0.2-0.4 \mathrm{~mL})$ were collected during the day (09:00-18:00 hours) after capture by hand by puncture from the brachial vein in heparinized capillaries within 2 minutes from burrow opening to the end of blood sampling. Blood samples were immediately transferred to $0.5 \mathrm{~mL}$ tubes and kept on ice until centrifugation. Plasma was stored frozen at $-20^{\circ} \mathrm{C}$. We sampled chicks at ca. 40 days of age (range 36-43 days, $\mathrm{N}=44$ in 2005, 31 in 2006, and 43 in 2007), and every 2-4 days during the pre-fledging period, depending on weather conditions. Only the last sample obtained of each chick, on the day before fledging or the previous day, was used as fledging CORT ( $\mathrm{N}=13$ in 2005, 15 in 2006, and 26 in 2007).

Plasma CORT levels were assessed by radioimmunoassay. Samples of the season 2005 were analyzed at the Max-Planck-Institut für Ornithologie (MPIO) in Andechs ${ }^{21}$ for plasma samples. The detection limit was $6.3 \mathrm{pg}$ per tube (63 pg/mL). The mean extraction recovery as determined by tritiated CORT added before the extraction was $90 \%$. The intra-assay variations of the two assays run for the 2005 samples were $7.1 \%$ and $17.3 \%$. The inter-assay variation was $5.7 \%$, and the interextraction variation of a chicken plasma pool was $3.4 \%$ for these two assays.

Samples of the seasons 2006 and 2007 were assayed at the Centre d'Etudes Biologiques de Chizé (CEBC). ${ }^{22}$ The mean extraction recovery as determined by tritiated CORT added before the extraction was $89 \%$. The samples of each season were run in one assay. The detection limit was $100 \mathrm{pg} / \mathrm{mL}$, and the lowest measurement was $0.3 \mathrm{ng} / \mathrm{mL}$. Intra-assay coefficient of variation was $12.6 \%(\mathrm{~N}=6$ duplicates $)$ in 2006 and $5.2 \%(\mathrm{~N}=6$ duplicates $)$ in 2007.

Using a subset of samples from the season $2007(\mathrm{~N}=17)$, we compared the CORT assay results obtained in both laboratories. We found that the assay used at the MPIO estimated higher CORT concentrations (Figures 1, 2), and this was more pronounced at higher concentrations. The relationship was best modeled by a cubic regression, using the MPIO values CORT $_{\text {MPIO }}$ as independent and the difference DIFF (MPIO - CEBC) as dependent variable $\left(\mathrm{DIFF}=-0.948476+0.059149 \times \mathrm{CORT}_{\mathrm{MPIO}}+\right.$ $0.004516 \times \mathrm{CORT}_{\mathrm{MPIO}}{ }^{2}-0.000006 \times \mathrm{CORT}_{\mathrm{MPIO}}{ }^{3} ; \mathrm{R}^{2}>0.999$, $P<0.001$ ). The very good fit (Figures 1,2 ) indicates that the changes are systematic and can be controlled for. We did this by subtracting the calculated concentration-dependent difference from the MPIO values (ie, standardizing to CEBC values).

\section{Data analysis}

Data analysis was carried out using SPSS software (version 17.0; SPSS Inc., Chicago, IL). Significance was set at $P<0.05$, and means are given with standard errors. We used ANOVA to compare chick parameters between years and general linear mixed models (GLMM) based on Type III sum of squares to test for the influence of time to fledging and difference between years simultaneously on CORT levels, while controlling for individual effects of chick identity. A general linear model (GLM) was used to test for age and year effect using only last measurement of each chick ( $0-2$ days before fledging), and results of this GLM were cited with effect sizes $\left(\eta^{2}\right)$.

As a measure of environmental variability, sea surface temperature anomaly (SSTA) data in the Falkland Current area adjacent to the Falkland Islands $\left(50-52^{\circ} \mathrm{S}, 61-63^{\circ} \mathrm{W}\right)$ were downloaded from http://ingrid.ldeo.columbia.edu/ SOURCES/.NOAA/.NCEP/.EMC/.CMB/.GLOBAL/. Reyn_SmithOIv2/.weekly/.ssta/ (Figure 2). It has been shown previously that sea surface temperatures were negatively correlated with provisioning frequencies to thin-billed prion chicks. $^{12}$ 


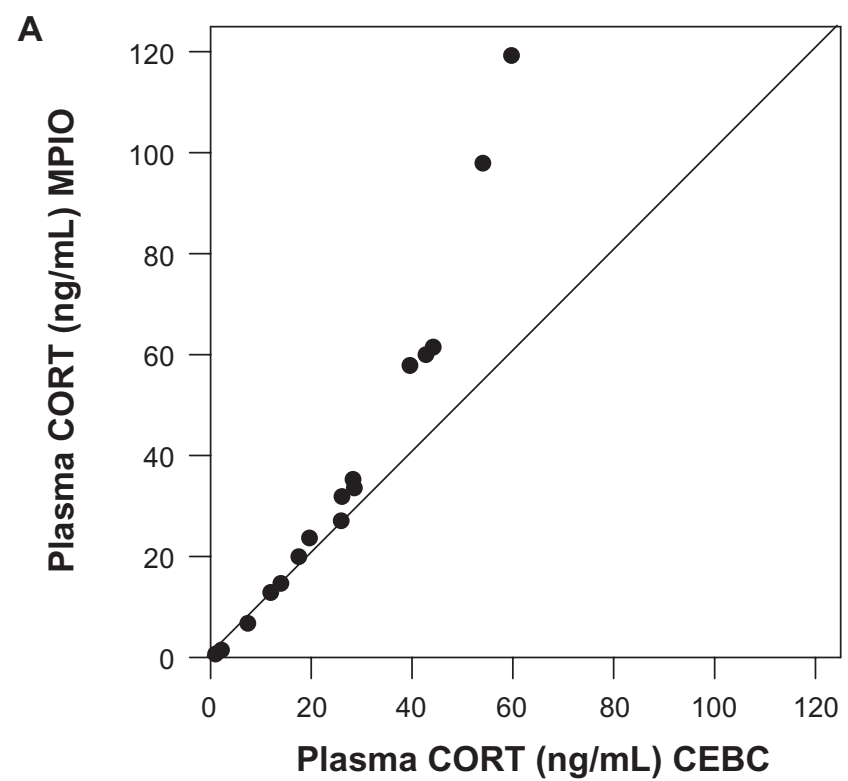

B

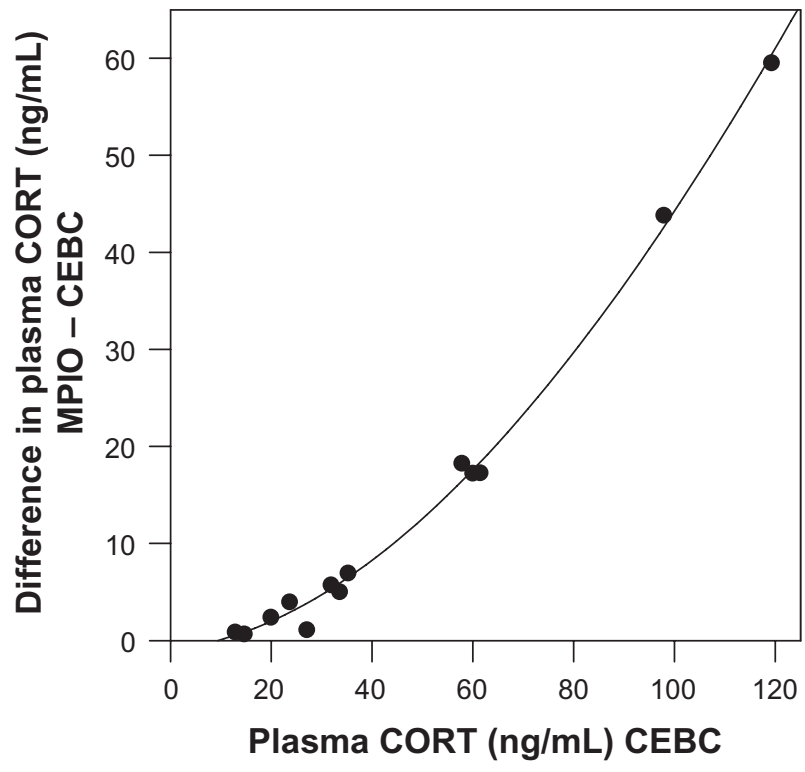

Figure I Plasma samples of thin-billed prion chicks measured in duplicate at MPIO and CEBC.

Abbreviations: CORT, corticosterone; MPIO, Max Planck Institute for Ornithology; CEBC, Centre d'Etudes Biologiques de Chizé.

\section{Results}

The seasons differed in sea surface temperatures (Figure 2). These differences were apparent during the course of the chick-rearing period (January-March) and especially pronounced in the fledging period. The sea surface water was warmer than average in 2005, near average in 2006, and colder than average in 2007 (Figure 2A). Inter-annual differences in chick condition mirrored the differences in environmental conditions (Figure $2 \mathrm{~B}$ and Table 1). The chicks were in the poorest condition in the warm year 2005, according to all measured parameters (Table 1), while
A

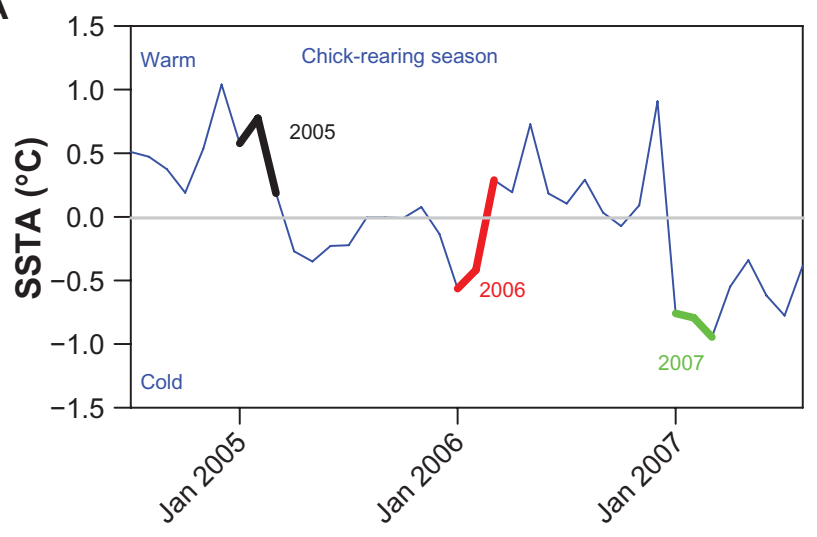

B

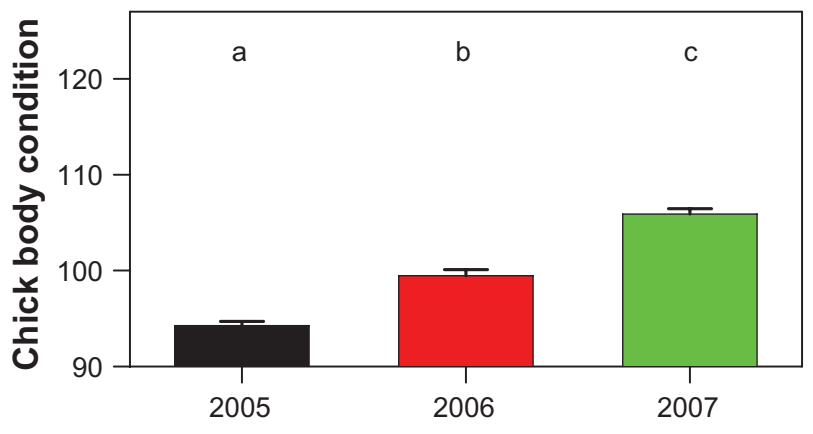

Figure 2 Sea surface temperature anomalies (SSTA) in the Falkland Current area adjacent to the Falkland Islands $\left(50-52^{\circ} \mathrm{S}, 6 \mathrm{I}-63^{\circ} \mathrm{W}\right)$, in the study period $(\mathbf{A})$, and mean chick body conditions (B). The chick-feeding periods (January-March) are marked in color. Source of the oceanographic data: http://ingrid.Ideo.columbia.edu/ SOURCES/.NOAA/.NCEP/.EMC/.CMB/.GLOBAL/.Reyn_SmithOlv2/.weekly/.ssta/

chicks of the year 2006 were in intermediate condition. The chicks of the colder year (ie, 2007) experienced the best conditions with high provisioning rates and high peak body masses. During this year, the chicks fledged younger and they also had low begging intensities and low circulating CORT (Table 1).

The chicks in the good season 2007 fledged younger, but reached the highest tail lengths at fledging (Table 1). Although the difference in wing lengths was not significant, the same order $(2005<2006<2007)$ as in the tails was observed (Table 1). In contrast to all observed differences, the body mass at fledging was not statistically different between years (Table 1).

In all seasons, chicks increased CORT concentrations in the days before fledging (Figure 3). The magnitude of this increase, however, differed between seasons (Figure 3). The well fed chicks of the season 2007 had the lowest CORT at fledging, with average values only $57 \%$ of the season 2005 (Table 1). A GLMM with pre-fledging CORT as dependent variable, year as independent categorical variable ('factor'), chick identity as random factor, and the number of days 
Table I Parameters reflecting the condition of thin-billed prions during their nestling period (condition parameters) and at the time of fledging (fledging parameters)

\begin{tabular}{|c|c|c|c|c|}
\hline Parameter & 2005 & 2006 & 2007 & ANOVA \\
\hline \multicolumn{5}{|l|}{ Condition parameters } \\
\hline Feeding rate $(\mathrm{g} / \text { day })^{*}$ & $23.8 \pm 0.6^{\mathrm{a}}$ & $24.1 \pm 0.8^{\mathrm{a}}$ & $27.1 \pm 0.5^{b}$ & $\mathrm{~F}_{2,135}=8.6, P<0.001$ \\
\hline Peak mass $(\mathrm{g})^{*}$ & $194.3 \pm 3.7^{\mathrm{a}}$ & $20 \mathrm{I} . \mathrm{I} \pm 5.4^{\mathrm{a}, \mathrm{b}}$ & $213.6 \pm 3.7^{b}$ & $F_{2,103}=6.1, P=0.003$ \\
\hline Duration of begging (minutes)* & $40.5 \pm 4.6^{\mathrm{a}}$ & $31.1 \pm 2.6^{b}$ & $15.1 \pm 0.8^{b}$ & $F_{2,65}=12.9, P<0.001$ \\
\hline Begging calls per session* & $1172 \pm 132^{\mathrm{a}}$ & $860 \pm 68^{b}$ & $402 \pm 27^{b}$ & $F_{2,65}=14.9, P<0.001$ \\
\hline CORT at 40 days $(\mathrm{ng} / \mathrm{mL})^{*}$ & $5.2 \pm 0.5^{\mathrm{a}}$ & $3.4 \pm 0.7^{\mathrm{a}}$ & $3.1 \pm 0.4^{b}$ & $F_{2,115}=5.3, P=0.006$ \\
\hline \multicolumn{5}{|l|}{ Fledging parameters } \\
\hline Fledging age (days)* & $53.5 \pm 0.5^{\mathrm{a}}$ & $54.1 \pm 0.4^{\mathrm{a}}$ & $51.8 \pm 0.4^{b}$ & $\mathrm{~F}_{91,2}=6.8, P=0.002$ \\
\hline Fledging mass (g) & $137.8 \pm 4.0$ & $137.0 \pm 2.9$ & $135.8 \pm 2.6$ & $\mathrm{~F}_{90,2}=0.1, P=0.915$ \\
\hline Fledging CORT (ng/mL)* & $23.1 \pm 2.9^{a}$ & $19.9 \pm 2.7^{\mathrm{a}, \mathrm{b}}$ & $13.3 \pm 1.1^{b}$ & $\mathrm{~F}_{50,2}=6.7, P=0.003$ \\
\hline Fledging wing length (mm) & $178.1 \pm 1.1$ & $178.8 \pm 1.2$ & $|8| .| \pm 1|$. & $F_{99,2}=1.8, P=0.172$ \\
\hline Fledging tail length $(\mathrm{mm})^{*}$ & $79.5 \pm 0.8^{\mathrm{a}}$ & $80.1 \pm 1 . I^{\mathrm{a}}$ & $84.3 \pm 0.8^{b}$ & $\mathrm{~F}_{99,2}=7.4, P=0.00 \mathrm{I}$ \\
\hline
\end{tabular}

Notes: Parameters which differed between the years are marked with *, and homogenous subsets determined by Tukey post-hoc tests are marked with identical superscript letters.

to fledging as covariable detected that both parameters significantly influenced the CORT concentration in the fledging period (GLMM: influence of year: $\mathrm{F}_{2,119}=7.9, P=0.001$; influence of days to fledging: $\left.\mathrm{F}_{1,110}=68.3, P<0.001\right)$. When only the last sample of each chick was included (taken 0-2 days before fledging), then the variability in pre-fledging CORT was explained by the year only (GLM: influence of year: $\mathrm{F}_{2,57}=6.0, P=0.005, \eta^{2}=0.181$; influence of days to fledging: $\left.\mathrm{F}_{1,147}=0.6, P=0.425, \eta^{2}=0.012\right)$.

Adult attendance at the nests in the pre-fledging period also differed between the years (Figure 4). The median number of nights in which chicks were not attended before fledging was 2 in 2005 and 2006, but 4 in 2007 (Kruskal-Wallis ANOVA on ranks: $\mathrm{H}=11.1$, d.f. $2, P=0.004)$. Post-hoc tests (Dunn's Method) revealed that 2007 differed from the

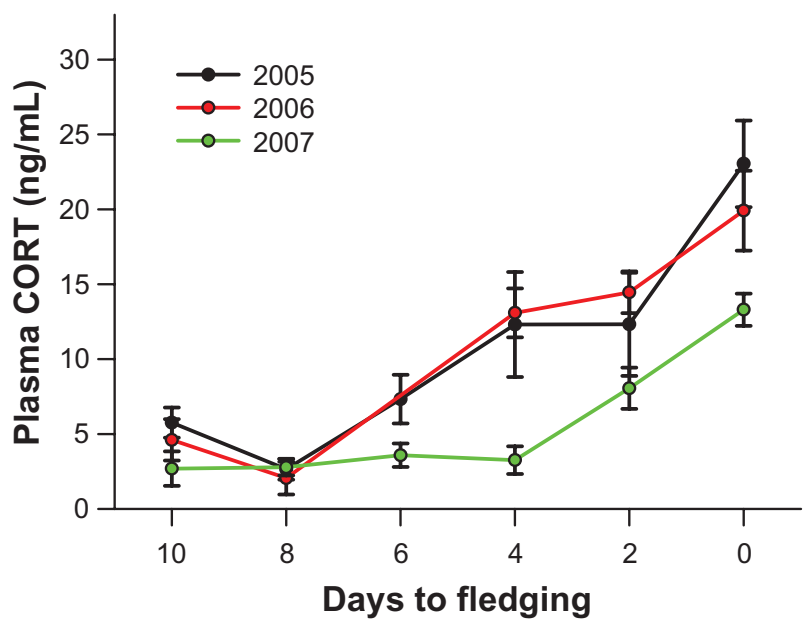

Figure 3 Pre-fledging increase in corticosterone (CORT) concentration in thinbilled prion chicks over three seasons of contrasting environmental conditions, starting 10 days before fledging. other two seasons; that is, chicks were left alone longer in the pre-fledging period in that year.

\section{Discussion}

We here used breeding seasons of differing environmental conditions as a natural experiment to investigate how basal levels of plasma CORT varied in chicks of thin-billed prions during the preparation for fledging.

CORT has been found to increase during the fledging and dispersal of juveniles of several cavity-nesting birds (American kestrels, Falco sparverius, ${ }^{23}$ screech owls, Otus asio and O. kennicottii ${ }^{24}$ pied flycatchers, Ficedula hypoleuca ${ }^{25}$ and thin-billed prions $\left.{ }^{3}\right)$, although the absence of a CORT increase before nest departure in snowy owls (Nyctea

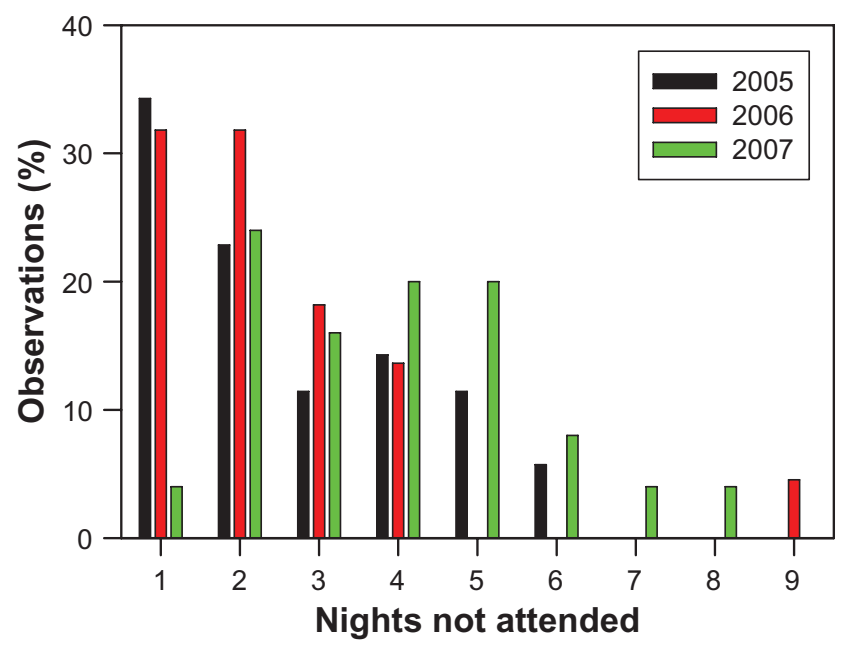

Figure 4 Pre-fledging parental absence of thin-billed prions in three breeding seasons. The number of nights from the last time an adult was registered to fledging of its chicks was recorded; for example, if the chicks were attended in the night before fledging, the parameter "nights not attended" was set to I, but if chicks were not attended for one or several nights, the parameters were set higher accordingly. 
scandiaca), suggests that this mechanism is not universal in birds. ${ }^{26}$ The present study suggested that the pre-fledging rise in CORT is influenced by differences in food availability experienced by the chicks. Chicks that had experienced chronic food shortages had a stronger rise in CORT just prior to fledging, and reached twice the concentration of CORT in plasma, compared with chicks in a good season. This is, to our knowledge, the first study to investigate such inter-annual differences and condition-dependence in pre-fledging CORT levels during the pre-fledging period. The results are in line with our previous findings that prefledging CORT levels are modified according to nutritional conditions. ${ }^{3}$ In that former analysis, we investigated whether unfed chicks had higher pre-fledging CORT levels than fed chicks, ie, a short-term influence of conditions. The present results are complementary and demonstrate the response to long-term conditions experienced by chicks on pre-fledging CORT levels. The cohort effect, ie, long-term conditions experienced by the chicks throughout the 2-month chickrearing period, even had a similar effect size to the timing effect of the pre-fledging CORT rise. In contrast to the peak body mass, the body mass of chicks at fledging did not differ among the years (Table 1). An excessive body mass would lead to a high cost of flight (high wing loading), and might therefore be avoided even under good conditions. Chicks raised during the colder season (2007) showed a lower prefledging rise in CORT (and then, showed a lower CORT level at fledging age, Table 1). Although chicks fledged at a younger age in 2007 than in previous years (see Table 1), the observed year effect is unlikely only due to younger chick age for the following reasons: (1) CORT levels at 40 days of age was already lower in 2007, and (2) the similar fledging wing length and even longer fledging tail length of chicks raised in 2007 indicate that the chicks of 2007 had a better body development at a younger age in comparison with previous years. This would most likely include the maturity of endocrinal functions.

In other previous studies of seabird chicks, contrasting patterns of condition-dependence were observed during the early or medium nestling period; for example, experimental food restriction resulted in elevated CORT levels in kittiwakes Rissa tridactyla ${ }^{27}$ and Rissa brevirostris, ${ }^{28}$ while decreased CORT levels were observed in undernourished tufted puffins (Fratercula cirrhata). ${ }^{29}$ The decrease may allow tufted puffin chicks to delay fledging, while avoiding detrimental effects of chronic CORT elevation. ${ }^{29}$ The difference in CORT patterns observed between petrel and auk chicks may be explained by the different processes of fledging: puffin chicks are not independent at fledging, but are still guarded and fed at sea. While in the nest, they receive food from two parents, but at sea only from the father. Thus, the costs and benefits of fledging underweight might be different to those in petrels, which are completely independent once fledged.

We further investigated whether the stronger rise observed in unfed chicks ${ }^{3}$ could be a response to failing adult attention. We observed that chicks were attended longer, mostly right up to fledging, in the poorer seasons, 2005 and 2006. The distribution of nights parents were absent before fledging (Figure 4) was very similar to that expected of adults attended at the same rate as during most of the chick-rearing period (eg, trip lengths 1-8 days, and intervals between feeds of $1-5$ days. ${ }^{11}$ In contrast, in the year 2007 a different distribution was observed, because many chicks were not attended in the last few days before fledging. The question whether chicks in Procellariiformes are deserted prior to fledging has been debated. ${ }^{30}$ The fact that chicks lose weight in the last days before fledging does not necessarily mean that the chick is no longer attended and fed, but it has been suggested that feeding may still occur at a lower rate. ${ }^{30}$ In thin-billed prions, as in at least 17 other species, ${ }^{31}$ adults regularly attend the nests even after the chick's departure. We observed this on several occasions in 2005 and 2006. On the other hand, some species have been reported to desert their chicks for longer periods before fledging, eg, a mean 9 days in Manx shearwaters (Puffinus puffinus), ${ }^{32} 12$ days in sooty shearwaters (Puffinus griseus), ${ }^{33}$ and 14 days in short-tailed shearwaters (Puffinus tenuirostris). ${ }^{34}$ The desertion periods observed in these larger species were long compared with thin-billed prion chicks in 2007 that were left alone for a mean 4 days. However, this difference corresponds well to the overall longer fledgling periods of these larger species. It would be instructive to see if these species also show facultative nest desertion only in good conditions, as suggested by the present study for thin-billed prions.

Our results are thus contrary to the hypothesis that chicks respond to being deserted by increasing their prefledging CORT levels. During the year of widespread prefledging desertion (2007), chicks had the lowest CORT levels close to fledging, although they were left alone for longer, compared with 2 years of infrequent desertion (2005 and 2006). Thus, the data suggest that poorer body condition of chicks, rather than failing adult attention explains the steeper rise in pre-fledging CORT levels observed in unfed chicks. ${ }^{3}$ 
In summary, we have shown here that the pre-fledging rise in CORT in a burrow-nesting seabird is modified according to the environmental conditions. CORT might play a pivotal role in mediating life-history tradeoffs; for example, tradeoffs between growth and immunocompetence. ${ }^{35} \mathrm{It}$ now remains to be explored which selective advantage a higher rise in CORT may give chicks in especially poor seasons such as those observed at the beginning of our study period, and how different fitness-related functions might be affected.

\section{Acknowledgments}

We are grateful to the New Island Conservation Trust for permission to work on the island and for providing accommodation and transport. We would like to thank Ian and Maria Strange for their support of this work. Anja Gladbach and Amanda Duckworth assisted with begging call counts. At the MPIO in Seewiesen, we thank Wolfgang Goymann for his support in the CORT assays, and in running duplicate samples to test inter-laboratory repeatability. At the CEBC, we thank Colette Trouvé, Stéphanie Dano, and André Lacroix for their excellent technical assistance in CORT assays. This study was funded by grants provided by the German Science Foundation DFG (Qu 148/1-ff) and approved by the Falkland Islands Government (Environmental Planning Office).

\section{Disclosure}

The authors report no conflicts of interest in this work.

\section{References}

1. Wingfield JC, Maney DL, Breuner CW, et al. Ecological bases of hormone-behavior interactions: the "emergency life history stage". Am Zool. 1998;38:191-206.

2. Wingfield JC, Kitaysky AS. Endocrine responses to unpredictable environmental events: stress or anti-stress hormones? Integr Comp Biol. 2002;42:600-609.

3. Quillfeldt P, Poisbleau M, Chastel O, Masello JF. Corticosterone in thin-billed prion Pachyptila belcheri chicks: diel rhythm, timing of fledging and nutritional stress. Naturwissenschaften. 2007;94: 919-925.

4. Devenport L, Knehans A, Sundstrom A, Thomas T. Corticosterone's dual metabolic actions. Life Sci. 1989;45:1389-1396.

5. Bourgeon S, Raclot T. Corticosterone selectively decreases humoral immunity in female eiders during incubation. J Exp Biol. 2006;209:4957-4965.

6. Cockrem JF, Potter MA, Candy EJ. Corticosterone in relation to body mass in Adelie penguins (Pygoscelis adeliae) affected by unusual sea ice conditions at Ross Island, Antarctica. Gen Comp Endocrinol. 2006; 149:244-252.

7. Baos R, Bortolotti GR, Marchant TA, Hiraldo F. Adrenocortical response to stress and thyroid hormone status in free-living nestling white storks (Ciconia ciconia) exposed to heavy metal and arsenic contamination. Environ Health Perspect. 2006;114:1497-1501.
8. Mueller C, Jenni-Eiermann S, Blondel J, et al. Effect of human presence and handling on circulating corticosterone levels in breeding blue tits (Parus caeruleus). Gen Comp Endocrinol. 2006;148:163-171.

9. Weimerskirch H, Chastel O, Ackermann L. Adjustment of parental effort to manipulated foraging ability in a pelagic seabird, the thinbilled prion Pachyptila belcheri. Behav Ecol Sociobiol. 1995;36: 11-16.

10. Duriez O, Weimerskirch H, Fritz H. Regulation of chick provisioning in the thin-billed prion: An interannual comparison and manipulation of parents. Can J Zool. 2000;78:1275-1283.

11. Quillfeldt P, Strange IJ, Segelbacher G, Masello JF. Male and female contributions to provisioning rates of thin-billed prions Pachyptila belcheri in the South Atlantic. J Ornithol. 2007;148:367-372.

12. Quillfeldt P, Strange IJ, Masello JF. Sea surface temperatures and behavioural buffering capacity in thin-billed prions Pachyptila belcheri: breeding success, provisioning and chick begging. J Avian Biol. 2007;38:298-308.

13. Quillfeldt P, McGill R, Masello JF, et al. Differences in the stable isotope signatures of seabird egg membrane and albumen - implications for non-invasive studies. Rapid Commun Mass Spectrom. 2009;23: 3632-3636.

14. Strange IJ. The thin-billed prion, Pachyptila belcheri, at New Island, Falkland Islands. Gerfaut. 1980;70:411-445.

15. Quillfeldt P, Masello JF, Strange IJ. Breeding biology of the thin-billed prion Pachyptila belcheri at New Island, Falkland Islands, in the poor season 2002/2003: egg desertion, breeding success and chick provisioning. Polar Biol. 2003;26:746-752.

16. Quillfeldt P, Michalik A, Veit-Köhler G, Strange IJ, Masello JF. Interannual changes in diet and foraging trip lengths in a small pelagic seabird, the thin-billed prion Pachyptila belcheri. Mar Biol. 2010;157: 2043-2050.

17. Quillfeldt P, Masello JF, Strange IJ, Buchanan KL. Begging and provisioning of thin-billed prions Pachyptila belcheri is related to testosterone and corticosterone. Anim Behav. 2006;71:1359-1369.

18. Masello JF, Quillfeldt P. Chick growth and breeding success of the burrowing parrot. Condor. 2002;104:574-586.

19. Duckworth A, Masello JF, Mundry R, Quillfeldt P. Age dependence and distribution of chick begging over the night in thin-billed prions. Pachyptila belcheri. Acta Orn. 2009;44:127-137.

20. Quillfeldt P, Poisbleau M, Mundry R, Masello JF. Are acoustical parameters of begging call elements of thin-billed prions related to chick condition? Acta Ethologica. 2010;13:1-9.

21. Goymann W, Trappschuh M, Jensen W, Schwabl I. Low ambient temperature increases food intake and dropping production, leading to incorrect estimates of hormone metabolite concentrations in European stonechats. Horm Behav. 2006;49:644-653.

22. Lormée H, Jouventin P, Trouve C, Chastel O. Sex-specific patterns in baseline corticosterone and body condition changes in breeding Red-footed Boobies Sula sula. Ibis. 2003;145:212-219.

23. Heath J. Corticosterone levels during nest departure of juvenile American kestrels. Condor. 1997;99:806-811.

24. Belthoff JR, Dufty AM Jr. Corticosterone, body condition and locomotor activity: a model for dispersal in screech-owls. Anim Behav. 1998;55:405-415.

25. Kern M, Bacon W, Long D, Cowie RJ. Possible roles for corticosterone and critical size in the fledging of nestling pied flycatchers. Physiol Biochem Zool. 2001;74:651-659.

26. Romero LM, Holt DW, Maples M, Wingfield JC. Corticosterone is not correlated with nest departure in snowy owl chicks (Nyctea scandiaca). Gen Comp Endocrinol. 2006;149:119-123.

27. Kitaysky AS, Piatt JF, Wingfield JC, Romano M. The adrenocortical stress response of Black-legged Kittiwake chicks in relation to dietary restrictions. J Comp Physiol B. 1999;169:303-310.

28. Kitaysky AS, Kitaiskaia EV, Wingfield JC, Piatt JF. Dietary restriction causes chronic elevation of corticosterone and enhances stress response in red-legged kittiwake chicks. J Comp Physiol B. 2001;171: 701-709. 
29. Kitaysky AS, Romano MD, Piatt JF, Wingfield JC, Kikuchi M. The adrenocortical response of tufted puffin chicks to nutritional deficits. Horm Behav. 2005;47:606-619.

30. Brooke M. Albatrosses and Petrels across the World. Oxford, UK: Oxford University Press; 2004.

31. Warham J. The Petrels. Their Ecology and Breeding Systems. New York, NY: Academic Press; 1990.

32. Harris MP. Breeding biology of the Manx shearwater Puffinus puffinus. Ibis. 1966;108:17-33.
33. Richdale LE. Biology of the Sooty shearwater Puffinus griseus. Proc Zool Soc Lond. 1963;141:1-117.

34. Serventy DL, Serventy V, Warham J. The Handbook of Australian SeaBirds. Sydney, Australia: Reed; 1971.

35. Brommer JE. Immunocompetence and its costs during development: an experimental study in blue tit nestlings. Proc R Soc Lond B. 2003;271:S110-S113.

\section{Publish your work in this journal}

Open Access Animal Physiology is an international, peer-reviewed, open access journal publishing original research, reports, reviews and commentaries on all areas of animal physiology. The manuscript management system is completely online and includes a very quick and fair peer-review system. Visit http://www.dovepress.com/ testimonials.php to read real quotes from published authors. 